\title{
HDS of 4,6-dimethyldibenzothiophene over CoMoS supported mesoporous
}

$\mathrm{SiO}_{2}-\mathrm{TiO}_{2}$ materials

B. Lebeau ${ }^{1,2^{*}}$, M. Bonne ${ }^{1,2}$, J. D. Comparot ${ }^{3}$, J. Rousseau ${ }^{3}$, L. Michelin ${ }^{1,2}$, J. L. Blin ${ }^{4}$, S. Brunet $^{3 *}$

${ }^{1}$ Université de Haute Alsace (UHA), CNRS, Institut de Science des Matériaux de Mulhouse (IS2M) UMR 7361, F-68100 Mulhouse, France,

${ }^{2}$ Université de Strasbourg, France

${ }^{3}$ Université de Poitiers /CNRS, IC2MP, UMR 7285, 86073 Poitiers Cedex 9 France.

${ }^{4}$ Université de Lorraine/CNRS, L2CM, UMR 7053, 54500 Vandoeuvre-lès-Nancy, France

\section{Corresponding authors}

Dr. Bénédicte Lebeau

Université de Haute Alsace (UHA), CNRS UMR 7361, Axe Matériaux à Porosité Contrôlée (MPC), Institut de Science des Matériaux de Mulhouse (IS2M),

$3 \mathrm{~b}$ rue Alfred Werner

F-68093 Mulhouse cedex, France

Tel. +33 389336882

E-mail: benedicte.lebeau@uha.fr

Dr. Sylvette Brunet

Institut de Chimie des Milieux et Matériaux de Poitiers (IC2MP) CNRS 7285

Université de Poitiers

B27-4 rue Michel Brunet TSA 5110686073 Poitiers Cedex 9 France tel: +33549453627

E-mail: sylvette.brunet@univ-poitiers.fr 


\begin{abstract}
$\mathrm{TiO}_{2}$ supported SBA-15 (xTi@SBA-15) materials with various high $\mathrm{TiO}_{2}$ loadings $(\mathrm{x}=25,50$ and $70 \mathrm{wt} \%)$ have been used as support for impregnation of CoMo active phase for the hydrodesulfurization (HDS) of 4,6-dimethyldibenzothiophene (46DMDBT) as model molecule representative of gazole cuts. Compared to CoMoS supported over pure commercial $\mathrm{TiO}_{2}$ and conventional $\mathrm{Al}_{2} \mathrm{O}_{3}$, a higher total activity was measured corresponding to the presence of isomerization and dismutation reactions due to Brönsted acidity of $\mathrm{TiO}_{2}$. However, the HDS activity remains higher using alumina as support. Moreover, the DDS pathway was found favored to the HYD one with sulfided CoMo supported over xTi@SBA-15 catalysts contrary with alumina as support.
\end{abstract}

Keywords: $\quad \mathrm{CoMoS} / \mathrm{TiO}_{2}, \quad$ CoMoS/SBA-15, CoMoS/mixedTiO $2-\mathrm{SBA}-15$, hydrodesulfurization, 46DMDBT 


\section{Introduction}

Due to their textural porous characteristics such as high surface area, regular and large pore size, ordered mesoporous silica materials have been identified as potentiel solid catalyst. The mesoporous silica SBA-15 is particularly studied because of its large wall thickness that makes this material more stable at environments such as those hydrotreatment reactions take place. However, the surface acidity of amorphous ordered mesoporous silica is low that is not favorable for many catalytic reactions. Surface modification with metallic element such as aluminum and titanium can improve the acidity properties of hydroxyl groups on the surface [1]. Ordered mesoporous silica materials can be used as catalyst support where an active phase can be deposited on the surface and the resulting composite will benefit of the structural and textural properties of the support associated to the catalytic properties of the active phase formed on the surface [2].

$\mathrm{TiO}_{2}$ is a semiconductor widely used for applications in electronics, electrochemical systems but also as catalyst, promoter or carrier for metals and their complexes. Due to its large bandgap it is a very efficient photocatalyst with anatase the most active crystalline phase [3]. For photocatalysis applications a high specific surface area is required for favoring molecule adsorption capacity and thus improving photocatalyst performance. Several strategies have been developed to produce mesoporous $\mathrm{TiO}_{2}$ with large specific surface area. However, the crystallization of $\mathrm{TiO}_{2}$ leads to the collapse of the porosity and thus reduces the molecule adsorption capacity [4]. The deposition of $\mathrm{TiO}_{2}$ on the surface of mesoporous silica is an elegant method for producing active photocatalyst with anatase nanocrystallites dispersed on the huge surface of a $\mathrm{SiO}_{2}$ thermally stable framework [5]. Moreover, the presence of $\mathrm{SiO}_{2}$ delays the phase transition anatase-to-rutile, which is preferable for photocatalytic properties since rutile is less active than anatase [6,7]. Our group has recently reported the synthesis of $\mathrm{TiO}_{2}-\mathrm{SiO}_{2}$ mesoporous composites with different $\mathrm{TiO}_{2}$ contents and the study of their catalytic 
properties for the photodegradation of methylorange dye in aqueous solution [8]. $\mathrm{TiO}_{2}$ is also well known to enhance the hydrodesulfurization (HDS) over Transition Metal Sulfides (TMS) by transferring electronic density towards the TMS [9]. For hydrodesulfurization of gazole or gasoline, $\mathrm{TiO}_{2}$ in mixture with alumina helps the dispersion of the active phase such as CoMo platelets on the surface and thus improves the catalytic activity [10]. However, as mentioned for photocatalysis purpose, the low specific surface area of conventional titania limits the loading of the adsorbed active species, involving a low catalytic efficiency. Nguyen et al [11] have recently used $\mathrm{TiO}_{2}-\mathrm{SiO}_{2}$ mesoporous composites for the HDS of thiophene and demonstrated the beneficial effect of such supports in which the silica SBA-15 framework confers adequate textural properties to the system and the active phase CoMoS benefits from the dispersive effect of $\mathrm{TiO}_{2}$. The synthesis method based on a wet impregnation with a subsequent solvent evaporation and followed by a thermal treatment is simple to implement and allows the deposition of various amounts of $\mathrm{TiO}_{2}$ on the surface of an ordered mesoporous silica. The nature of the generated $\mathrm{TiO}_{2}$ phase is dependent on the titania amount and on the porous texture of the silica support. Depending on the $\mathrm{TiO}_{2}$ structures in the composites, they can orient the growth and morphology of CoMoS platelet that can affect HDS performances [12]. Moreover, the acidity of the composite support, will also play on the catalytic performances of the resulting material [13]. Indeed, as reported previously for the transformation of 4,6-dimethyldibenzothiophene (46DMDBT) a model molecule representative of the most refractory sulfur compounds for amount less than $250 \mathrm{ppm} \mathrm{S}$ in gazole cuts, new reactions were observed. In addition of the main direct desulfurization (DDS) and hydrogenation (HYD) ways involved over the conventional CoMoS or NiMoS over alumina catalysts, isomerization and dismutation ways were observed [14-16]. Moreover, depending on the support properties, modification of selectivities towards the DDS and HYD ways were involved. With zeolite as support, the contribution of the DDS way increases due 
to the isomerization and dismutation reactions [14]. Conversely, with $\mathrm{TiO}_{2}$ as support, a modification of the selectivity happens in comparison with alumina, direct DDS way becomes the main way where the impact of the isomerization and dismutation are not in the majority $[15,16]$.

Few studies over CoMoS supported $\mathrm{TiO}_{2}$-SBA-15 composites have been reported for the HDS of dibenzothiophene (DBT) and 46DMDBT as model molecules. [17-22]. The presence of small amount of Ti incorporated in SBA15 structure had a positive effect in the dispersion of the CoMoS phase, the sulphurization of cobalt and on the number of CUS (coordinated unsaturated sites) active sites corresponding to the modification of the interaction with the support. The consequence was a higher activity in DBT and 46DMDBT transformations with a modification of DDS and HYD selectivities [17-19].

In the present paper, various CoMo supported over Ti@SBA-15 catalysts were prepared with various amount of Ti and SBA-15 silica (xTi@SBA-15) as support. Ti@SBA-15 catalysts have been prepared by post-impregnation of SBA-15 with high Ti loading varying from 25 to 70 wt $\%$ of $\mathrm{TiO}_{2}$. The CoMoS/xTi@SBA-15 solids were evaluated for the 4,6dimethyldibenzothiophene (46DMDBT) transformation and relations between their performances (in terms of activity and selectivities) and their physico-chemical properties are discussed.

\section{Materials and methods}

Chemical reagents were purchased from Sigma-Aldrich: amphiphilic triblock copolymer pluronic P123 $\left(\left(\mathrm{CH}_{2} \mathrm{CH}_{2} \mathrm{O}\right)_{20}\left(\mathrm{CH}_{2} \mathrm{CH}\left(\mathrm{CH}_{3}\right) \mathrm{O}\right)_{70}\left(\mathrm{CH}_{2} \mathrm{CH}_{2} \mathrm{O}\right)_{20}\right)$ used as porogen agent; tetraethylorthosilicate (TEOS, $\left.\mathrm{Si}(\mathrm{OEt})_{4}\right)$ and titanium isopropoxide (TIP, $\mathrm{Ti}\left(\mathrm{O}^{\mathrm{i}} \mathrm{Pr}\right)_{4}, 97 \%$ ) used as inorganic precursors ; cobalt(II) nitrate hexahydrate $\left(\mathrm{CoN}_{2} \mathrm{O}_{6}, 6 \mathrm{H}_{2} \mathrm{O}, 99.00 \%\right)$ and 
ammonium heptamolybdate $\left[\left(\mathrm{NH}_{4}\right)_{6} \mathrm{Mo}_{7}, 6 \mathrm{H}_{2} \mathrm{O}, 99.98 \%\right]$ used as $\mathrm{Co}$ and Mo precursors, respectively.

\subsection{Supports preparation and impregnation}

$\mathrm{TiO}_{2} @ \mathrm{SBA}-15$ supports were prepared as previously reported from SBA-15 $\mathrm{SiO}_{2}$ synthesized at $90^{\circ} \mathrm{C}$ and calcined at $300^{\circ} \mathrm{C}$ with 25,50 and $70 \mathrm{wt} \%$ of $\mathrm{TiO}_{2}$ [8]. The synthesis of the SBA15 silica material was realized according to the modified protocol of Zhao et al [23] by Belmoujahid et al [24]: after dissolution of pluronic P123 in hydrochloric solution at $40^{\circ} \mathrm{C}$, the silica source TEOS was added under stirring and the mixture with a molar composition of 1 TEOS: 0.017 P123: $5.68 \mathrm{HCl}: 197 \mathrm{H}_{2} \mathrm{O}$ was left $2 \mathrm{~h}$ at $40^{\circ} \mathrm{C}$. Then the mixture was transferred in a closed polypropylene bottle and left for $24 \mathrm{~h}$ in an oven at $90^{\circ} \mathrm{C}$ under static conditions. The solid was recovered by Büchner filtration, washed with distilled water and dried in an oven at $70^{\circ} \mathrm{C}$ for one night. The porogen agent $\mathrm{P} 123$ was removed by calcination under air at $300^{\circ} \mathrm{C}$ for $4 \mathrm{~h}$. A volume of $\mathrm{Ti}(\mathrm{OiPr})_{4}$ corresponding to the desired titania loading was diluted in $20 \mathrm{~mL}$ of dry ethanol and slowly added to the silica support in order to prepare $1 \mathrm{~g}$ of $\mathrm{TiO}_{2} @ \mathrm{SBA}-15$ composite. The solvent was evaporated under stirring at room temperature and the solid was fully dried at $70{ }^{\circ} \mathrm{C}$ for one night. The composite was then calcined at $400{ }^{\circ} \mathrm{C}$ under air during 4 hours in order to form $\mathrm{TiO}_{2}$-based phase. After preparation and characterization, all the mesoporous Ti@SBA-15 supports (labelled x Ti@SBA-15 with $\mathrm{x}=\mathrm{wt} \% \mathrm{TiO}_{2}$ ) were impregnated as reported previously by metallic Co and Mo precursors in order to have a number of Mo atoms per $\mathrm{nm}^{2}$ and a Co/Mo ratio of 3 and 0.54 , respectively $[15,16]$. The precursors were decomposed at $380^{\circ} \mathrm{C}$ under air atmosphere. The various prepared catalysts were named CoMo/xTi@SBA15 with x equal to 25, 50 and 75 corresponding to the amount of $\mathrm{Ti}(\mathrm{wt} \%)$. 


\subsection{Catalytic measurements}

The CoMo/xTi@SBA-15 solids were firstly sulfided in situ (to become CoMoS/ xTi@SBA15) in a fixed flow reactor using a sulfiding feed made of $4.75 \%$ by volume of dimethyl disulfide (DMDS) in n-heptane as solvent under a 4.0 MPa of total pressure. After 14 hours at $350^{\circ} \mathrm{C}$ the temperature was then cool down to the reaction temperature $\left(340^{\circ} \mathrm{C}\right)$ as previously described $[15,16]$. Then, the transformation of $46 \mathrm{DMDBT}$ was carried out at $340^{\circ} \mathrm{C}$ and 4.0 $\mathrm{MPa}$ of total pressure. The feed was composed by 46DMDBT (500 ppm S) and dimethyl disulfide (DMDS) (9500 wt ppm S) diluted into n-heptane as solvent. The total amount of sulfur (1wt \%) was representative of the amount of $\mathrm{S}$ contained in a real gazole feedstock. DMDS was the precursor of $\mathrm{H}_{2} \mathrm{~S}$.

The reaction scheme of the HDS of 46DMDBT is in afreement with previous studies [14-16] (Scheme 1). Indeed, two main routes are involved: i) HYD route involving the partial hydrogenation of the reactant followed by C-S bond rupture to produce to the desulfurized product $(\mathrm{MCHT})$, ii) the direct desulfurization (DDS) pathway leading to the formation of DMBPh. With a conventional $\mathrm{CoMo} / \mathrm{Al}_{2} \mathrm{O}_{3}$ catalyst, the main route is the hydrogenation (HYD) pathway with a selectivity of $75 \%$. Over acidic support such as zeolite or mesoporous $\mathrm{TiO}_{2}$ [14-16], isomerization and dismutation reactions are also involved leading to the formation of alkylmethyldibenzothiophenes and the corresponding desulfurized products by direct C-S bond rupture.

Different activities (A) of the various catalysts were calculated in order to evaluate the contribution of each route $[15,16]$. $A_{\text {Total }}, A_{\text {acid }}$ (isom+dism.), $A_{H D S}, A_{H Y D}, A_{D D S}$ direct, $A_{D D S}$ acid, $A_{\text {acid. }}$ They are defined as the number of moles of sulfur compounds transformed by each way for the transformation of 46DMDBT per gram of catalyst, per square meter and per Mo.atom. 
More precisely, $\mathrm{A}_{\text {Total }}$ corresponds to the global transformation of 46DMDBT, $\mathrm{A}_{\text {acid }}$ to the sulfided compounds formed by isomerization and dismutation reactions of 46DMDBT and $A_{H D S}$ to the sum of the total desulfurized products through DDS and HYD ways $\left(\mathrm{A}_{\mathrm{HYD}}+\right.$ $A_{D D S}$ direct $+A_{D D S}$ acid). $A_{H Y D}$ is calculated from the MCHT formation, $A_{\text {direct DDS }}, A_{D D S}$ Acid.. refer to the amount of desulfurized products resulting from the direct desulfurization (formation of $\mathrm{DMBPh}$ ), and from the acid ways (isomerization and dismutation) of 46DMDBT, respectively.

The selectivity towards DDS and HYD are defined as the ratio between the sum of the activities of the DDS routes and the HDS activity. Conversely, the selectivity towards HYD corresponds to the ratio between the activity of HYD way and the HDS activity. Activities are calculated at isoconversion of 46DMDBT (around 25\%).

The contact time defined as the ratio between the volume of the catalyst and the gas flow of the reactant was adapted in order to obtain a conversion of 46DMDBT of around $25 \%$ for all the solids.

The reactor effluents were condensed and liquid samples were periodically collected to be analyzed by gas chromatography. Gaseous products were not found except for methane which was produced by dimethyl disulfide decomposition. Analyses were carried out with a Agilent Technologies 7820A equipped with a 25 m BP1 (SGE) capillary column (inside diameter: $0.32 \mathrm{~mm}$; film thickness : $5 \mu \mathrm{m})$ with a temperature program from 50 to $70^{\circ} \mathrm{C}\left(4^{\circ} \mathrm{C} / \mathrm{min}\right)$ then from 70 to $250^{\circ} \mathrm{C}\left(15^{\circ} \mathrm{C} / \mathrm{min}\right)$.

\subsection{Material characterization}

Powder X-ray diffraction patterns of supports were recorded at low and wide angles using a Panalytical X'Pert PRO diffractometer equipped with a $\mathrm{Cu}$ X-ray tube $\left(\lambda_{\mathrm{Cu}(\mathrm{K} \alpha)}=0.1542 \mathrm{~nm}\right)$ operating at $45 \mathrm{kV}$ and $40 \mathrm{~mA}$ and an $\mathrm{X}^{\prime}$ Celerator detector. Fixed divergence slit (1/16), mask 
$(10 \mathrm{~mm})$ and antiscatter slit $(1 / 8)$ were used at primary beam for the current analysis. Small Angle X-ray Scattering (SAXS) patterns of CoMo supported xTi@SBA-15 were carried out on a SAXSess $\mathrm{mc}^{2}$ instrument (Anton Paar), using a line collimation system. This instrument is attached to a ID 3003 laboratory X-Ray generator (General Electric) equipped with a sealed X-Ray tube (PANalytical, $\lambda_{\mathrm{Cu}, \mathrm{K} \alpha}=0.1542 \mathrm{~nm}$ ) operating at $40 \mathrm{kV}$ and $50 \mathrm{~mA}$. A multilayer mirror and a block collimator provide a monochromatic primary beam. A translucent beam stop allows the measurement of an attenuated primary beam at $\mathrm{q}=0$. Mesoporous materials were put between two sheets of Kapton ${ }^{\circledR}$ placed in a powder cell before being introduced inside the evacuated chamber. All data were corrected for the background scattering from the Kapton ${ }^{\circledR}$ and for slit-smearing effects by a desmearing procedure from SAXSQuant software using the Lake method. Raman Scattering Spectra were collected on xTi-SBA-15 materials before and after CoMo impregnation with a Jobin-Yvon T64000 spectrometer equipped with an optical microscope in confocal mode. The excitation beam $(514.5 \mathrm{~nm})$ was focused using a long-frontal x50 objective (numerical aperture 0.5 ) on an area of about $3 \mu \mathrm{m}^{2}$. The laser power on the sample was approximately $10 \mathrm{~mW}$. The spectral resolution was $3 \mathrm{~cm}^{-1}$, with a wavenumber precision better than $1 \mathrm{~cm}^{-1}$. Solid-state UV-Vis spectra of xTi-SBA-15 supports were recorded on a PerkinElmer equipped with integration sphere.

$\mathrm{N}_{2}$ adsorption-desorption isotherms before and after CoMo impregnation were determined on a Micromeritics TRISTAR 3000 sorptometer at $-196{ }^{\circ} \mathrm{C}$. The specific surface area was obtained by using the BET (Brunauer, Emmett, Teller) model whereas the pore diameter and the pore size distribution were determined by the BJH (Barret, Joyner, Halenda) method applied to the adsorption branch [25,26]. Elemental analysis of the CoMo impregnated samples was performed by wavelength dispersive X-ray fluorescence spectrometry (XRF) using a PHILIPS MagiX apparatus. For this analysis, the sample powder was pelletized under a pressure of 4 tons for 2 minutes with a hydraulic press. XPS spectra of CoMo and CoMoS 
supported over xTi@SBA-15 materials were collected on a Kratos Axis Ultra (Kratos Analytical, U.K.) spectrometer with a hemispherical energy analyzer and using a monochromatic Al $\mathrm{K} \alpha$ source $(1486.6 \mathrm{eV})$. All spectra were recorded at a $90^{\circ}$ takeoff angle, with the analyzed area being currently about $0.7 \times 0.3 \mathrm{~mm}$. Survey spectra were acquired with $1.0 \mathrm{eV}$ step and $160 \mathrm{eV}$ analyzer pass energy and the high-resolution regions with $0.1 \mathrm{eV}$ step and $20 \mathrm{eV}$ pass energy (instrumental resolution better than $0.5 \mathrm{eV}$ ). The, Co $2 \mathrm{p}$, Mo $3 \mathrm{p}$, Mo 3d, S 2s and S 2p binding energies were referenced to the $\mathrm{C} 1 \mathrm{~s}$ line situated at $284.6 \mathrm{eV}$, i.e. the value generally accepted for adventitious carbon surface contamination [27].

The CoMo/xTi@SBA-15 sulfided solids were packed in schlenk under argon to avoid sulfate formations. They were identified with reference samples drawn from the Handbook of X-ray photoelectron spectroscopy [28], NIST X-ray Photoelectron Spectroscopy Database (NIST Standard Reference Database 20, Web Version 3.4). For each catalyst, the metal and sulfur peaks have been identified according to their binding energies [16, 29, 30]. The elemental surface composition of the catalysts, and therefore, the sulfur/metal atomic ratio $(\mathrm{S} / \mathrm{Me})$ and the active phase evolution after reaction were determined from the area of the metal and sulfur peaks (the uncertainty of the value is around 20\%).

A JEOL JEM2100F transmission electron microscope (TEM) was used to characterize the The CoMo/xTi@SBA-15 sulfided solids and more precisely the $\mathrm{MoS}_{2}$ phase.

The measurement of the acidity by adsorption of pyridine followed by FTIR spectroscopy was carried out with a ThermoNicolet NEXUS 5700 spectrometer at a resolution of $2 \mathrm{~cm}^{-1}$ and collected 128 scans per spectrum. Catalyst samples were pressed into thin pellets (10-60 mg) with diameter of $16 \mathrm{~mm}$ under a pressure of $1-2 \mathrm{t} . \mathrm{cm}^{-2}$ and activated in situ during one night under nitrogen at $380^{\circ} \mathrm{C}$. After cooling down the samples until room temperature, a background spectrum was collected. The quantity of Lewis and Brönsted acid sites was determined from the area of the band at $1445-1450 \mathrm{~cm}^{-1}$ for the Lewis acidity and at $1540 \mathrm{~cm}^{-}$ 
${ }^{1}$ for the Brönsted acidity [31]. All spectra were normalized to an equivalent sample mass (20 $\mathrm{mg}$ ) to compare them against each other.

\section{Results}

\subsection{Characterization of CoMo/xTi@SBA-15 materials}

\subsection{1. xTi@SBA-15 supports}

Before CoMo impregnation, the low angle XRD patterns of parent SBA-15 and 25Ti@SBA15 composite present 3 diffraction peaks corresponding to the planes [100], [110] and [200] indicating a 2D hexagonal mesostructure characteristics of SBA-15 materials (Fig. S1a). Only 2 reflections (100) and 110 are observed for the 50Ti@SBA-15 composite and one broad (100) for the 70Ti@SBA-15 composite, which indicate the partial collapse of the mesostructure of the parent SBA-15 with increasing Ti loading, probably upon the formation of the $\mathrm{TiO}_{2}$-based phase. The $\mathrm{N}_{2}$ adsorption/desorption nitrogen isotherms of SBA-15 and xTi@SBA-15 supports are type IV with a $\mathrm{H} 1$ hysteresis that becomes $\mathrm{H}_{2}$ type with increasing Ti-loading: mesopores become partially occluded indicating deposition of Ti species inside (Fig. S2a). The structural and textural characteristics of the parent SBA-15, xTi@SBA-15 and CoMo/xTi@SBA-15 solids are reported in Table 1.

A proportional decrease of the BET specific surface area, pore volume and pore diameter with increase of $\mathrm{TiO}_{2}$ loading is observed for xTi@SBA-15 (Fig S2b). The decrease of textural characteristics is mainly due to the addition of dense Ti-based phases, but also to a partial mesopore filling and collapse of the mesostructure. The XRD patterns of the xTi@SBA-15 at wide angles display peaks characteristics of anatase phase (Fig. S1b). The intensity increases and the width at half-height decrease with increasing $\mathrm{TiO}_{2}$ content indicating a higher rate of crystallization and larger anatase crystallites. The presence of anatase was also confirmed by Raman and UV-Vis spectroscopies (Fig. 1a,b). Indeed, all xTi@SBA-15 support displays 
Raman bands at 142, 197, 396, 520 and $643 \mathrm{~cm}^{-1}$ characteristic of anatase that are low intense for 25Ti@SBA-15 (Fig. 1a) [32,33]. On UV-Vis spectra displayed on Fig. 1b a multicomponent band with maxima at about 220, 265 and $300 \mathrm{~nm}$ is present for composites in the $200-400 \mathrm{~nm}$ range. The band at bear $220 \mathrm{~nm}$ corresponds to $\mathrm{Ti}$ in a nearly tetrahedral coordination $\left[(\mathrm{Si}-\mathrm{O})_{4}-\mathrm{Ti}\right]$ (band at near $220 \mathrm{~nm}$ ), the one at $265 \mathrm{~nm}$ to $\mathrm{Ti}$ in a nearly octahedral coordination, probably with chain-type $\mathrm{Ti}-\mathrm{O}-\mathrm{Ti}$ and/or $\mathrm{Ti}-\mathrm{O}-\mathrm{Si}-\mathrm{O}-\mathrm{Ti}$ structures, and the one at about $300 \mathrm{~nm}$ with a tail extending in the $300-350 \mathrm{~nm}$ region, particularly for 70Ti@SBA-15, indicates the presence of titania nanoparticles [34].

\subsubsection{CoMo supported xTi@SBA-15 materials}

For the CoMo supported over xTi@SBA-15 materials only the peak corresponding to the (100) reflection was observed by SAXS indicating a partial collapse of the mesostructure. A strong decrease of specific surface areas and pore volume was observed (about 75, 70, 50 and $60 \%$ for both specific area and pore volume in CoMo/SBA-15, CoMo/25Ti@SBA-15, CoMo/50Ti@SBA-15 and CoMo/70Ti@SBA-15, respectively) (Table 1). Textural modification cannot be explained only by the addition of CoMo species and, as observed by SAXS, is a consequence of partial collapse of the mesostructure upon impregnation and subsequent thermal treatment.

The Raman spectra of CoMo supported over xTi@SBA-15 materials display band characteristic of anatase at 151-154, 197-201, 395-396, 507-510 and 631-634 $\mathrm{cm}^{-1}$ (Fig. 2a). An additional band characteristic of the vibrations associated to molybdenum species is clearly observed at $939-940 \mathrm{~cm}^{-1}$ for 25Ti@SBA-15 and 70Ti@SBA-15. This band is attributed to the presence of terminal $\mathrm{Mo}=\mathrm{O}$ sites [35] (Fig. 2b). More precisely, this band indicates the presence of polymolybdate species and/or the presence of crystalline $\mathrm{CoMoO}_{4}$ [36]. Such species are reported to make difficult the sulfidation [37]. 
For the three CoMo supported over xTi@SBA-15 catalysts, the XPS high resolution Ti 2p spectra display $2 \mathrm{p} 3 / 2$ and $2 \mathrm{p} 1 / 2$ components located at around $458.6 \mathrm{eV}$ and $464.4 \mathrm{eV}$, respectively (Fig. S3), in agreement with those of $\mathrm{TiO}_{2}$ anatase reported in the literature [21]. They indicate that titanium exists as $\mathrm{Ti}$ (IV) species, being attributed to $\mathrm{Ti}^{4+}$. In addition, the Mo 3d high resolution spectra display two main $3 \mathrm{~d} 5 / 2$ and $3 \mathrm{~d} 3 / 2$ components located at 232.4 $\mathrm{eV}$ and $235.6 \mathrm{eV}$, respectively (Fig. S3). These binding energies are consistent with Mo in an oxidic environment $[35,38]$. Finally, the Co 2 p3/2 main peak arises at around $781.3 \mathrm{eV}$ (Fig. S3) [39]. The Co/Mo surface ratio, evaluated from the XPS analysis, varies from 0.54 to 0.57 with a $\mathrm{Co} /(\mathrm{Co}+\mathrm{Mo})$ ratio located between 0.35 and 0.36 . The $\mathrm{Co} / \mathrm{Mo}$ and $\mathrm{Co} /(\mathrm{Co}+\mathrm{Mo})$ ratios determined by X-ray fluorescence analyses (Table 2) are slightly higher than the ones obtained by XPS, suggesting that cobalt and molybdenum are not homogeneously distributed on the surface and in the bulk. The number of Mo atoms per $\mathrm{nm}^{2}$ is evaluated between 4.1 and 6.8, depending on the support (Table 2). Both techniques, XRF and XPS, allow concluding that the metals have been effectively dispersed onto the supports' surface. In addition, we can note that the number of Mo atoms per $\mathrm{nm}^{2}$, the $\mathrm{Co} /(\mathrm{Co}+\mathrm{Mo})$ and the $\mathrm{Co} / \mathrm{Mo}$ ratios are very closed to the targeted ones, i.e. 3 Mo atom $/ \mathrm{nm}^{2}, 0.35$ and 0.54 , respectively.

The acidity properties of the CoMo supported xTi@SBA-15 materials have been characterized by FTIR after pyridine adsorption (Table 3). Results concerning the CoMo supported over conventional $\mathrm{Al}_{2} \mathrm{O}_{3}$ catalyst and commercial $\mathrm{TiO}_{2} \mathrm{P} 25$, which will be used as reference catalysts for the hydrotreatment reactions, are also given in Table 3. Reference material P25 was impregnated under the same conditions than the xTi@SBA-15 ones. As expected the Lewis acidity is high for xTi@SBA-15 supports due to the presence of $\mathrm{TiO}_{2}$. In addition, they also exhibit a noticeable Brönsted acidity, which is assume to be due to the presence of the amorphous $\mathrm{TiO}_{2}$ [40]. Indeed, in these nanocomposites the crystallization in anatase is partial [8]. By contrast, a very low Brönsted acidity, $0.08 \mu \mathrm{mol} . \mathrm{m}^{-2}$ or $3 \mu \mathrm{mol} . \mathrm{g}^{-1}$ 
was measured for P25 and no Brönsted acidity was detected for the conventional CoMo/ $\mathrm{Al}_{2} \mathrm{O}_{3}$ catalyst. The very low amount of Brönsted site after impregnation, measured for P25 (75\% of anatase $+25 \%$ rutile) reinforces our hypothesis. Moreover, in a paper dealing with the hydrothermal synthesis and acidity characterization of $\mathrm{TiO}_{2}$ polymorphs, Afanasiev et al [41] have shown that strong Lewis acid sites predominate on anatase and rutile surface but not Brönsted ones. It is noteworthy that the Brönsted acidity of the CoMo supported over SBA-15 is low due to the absence of Ti species.

\subsection{Characteristics of the sulfided CoMoS/xTi@SBA-15 materials}

The sulfided molybdenum based catalysts supported over various supports and promoted by cobalt have been characterized by XPS after the sulfidation step to determine the surface composition. For example, the corresponding XPS spectra of molybdenum, cobalt and sulfur corresponding to CoMoS/70Ti@SBA-15 are shown respectively (Fig. 3). Similar results were observed for the other samples (not reported here).

Table 4 resumes all of the $\mathrm{S} / \mathrm{Mo}, \mathrm{Co} / \mathrm{Mo}$ atomic ratios, the promotion by cobalt (PR), S/Mo atomic ratios, the sulfidation rate of molybdenum (TSMo) and the global sulfidation rate (TSG). Taking into account the uncertainty (around 20\%), the S/Mo ratio and the global sulfidation rate (TSG) are in the same range and equal to 2 and about $60 \%$ and for the solids with various supports, respectively. This clearly demonstrates that the $\mathrm{MoS}_{2}$ phase is well formed in all cases. Similar Co/Mo ratio is also observed whatever the solids and close to the theoretical value (0.5). Regarding, the total sulfidation rate of molydenum (TSMo), a very low value was determined for $\mathrm{TiO}_{2}-\mathrm{P} 25$ in comparison of the others supports (only $40 \%$ instead around $70 \%$ for $\mathrm{Al}_{2} \mathrm{O}_{3}$ ) which means a low amount of molybdenum sulfidation. As reported previously in a recent paper [16] and in the literature [22], since the interaction between the active metal and support is inversely proportional to the Mo sulfidation, this means that 
weaker interactions occur between $\mathrm{Mo}$ and $\mathrm{Al}$ than between Mo and $\mathrm{Ti}$ or Si. The TSMo values (around 60\%) determined for 25Ti@SiBA15 and 70Ti@SiBA15 are also lower to the one of the conventional $\mathrm{Al}_{2} \mathrm{O}_{3}$ catalyst $(70 \%)$ that may be explained by the presence of $\mathrm{CoMoO}_{4}$ species that have been reported to be difficult to be sulfided [37].

TEM analysis of CoMoS over 70Ti@SBA-15, 50Ti@SBA-15 or SBA-15 confirmed the formation of $\mathrm{MoS}_{2}$ slabs (Fig. 4, 5 and 6, respectively). However, differences were observed between pure SBA-15 and xTi@SBA-15 as supports. Indeed, over pure SBA-15, MoS 2 slabs were observed homogeneously on the surface (Fig. 5). Over xTi@SBA-15, taking account that the support was not homogeneous but composed by amorphous SBA-15 and $\mathrm{TiO}_{2}$ crystals, the $\mathrm{MoS}_{2}$ slabs did not present the same characteristics (Fig. 4 and 5). Indeed, $\mathrm{MoS}_{2}$ are isolated in the SBA-15 part and surrounded $\mathrm{TiO}_{2}$ crystals. The stacking of the $\mathrm{MoS}_{2}$ slabs varies from 1 to 6 with a length of $10 \mathrm{~nm}$ for the SBA-15 part against 1 to 3 around $\mathrm{TiO}_{2}$ crystals with a length of 10-20 nm for the 2 amount of Ti (50Ti@SBA-15, 70Ti@SBA-15). These characteristics are different with pure SBA-15 (Figure 6a) as support where $\mathrm{MoS}_{2}$ slabs have a stack ranging from 1 to 6 with a length of less than $10 \mathrm{~nm}$. In comparison, with $\mathrm{Al}_{2} \mathrm{O}_{3}$ as support (the conventional catalyst) it can be seen that xTi@SBA-15 (Fig. 4 and 5) and SBA-15 (Fig. 6a) supports involve a decrease of the length of the $\mathrm{MoS}_{2}$ slabs which varies in the range from 20 and $50 \mathrm{~nm}$ with stacking of 1.7 for the conventional $\mathrm{Al}_{2} \mathrm{O}_{3}$ support (Fig. $6 \mathrm{~b}$ ) according to the literature [21].

\subsection{HDS of 46DMDBT over CoMoS/xTi@SBA-15 catalysts}

The performances (activity and selectivities) of the various CoMoS/xTi@SBA-15 solids were evaluated for the transformation of 46DMDBT. No catalyst deactivation were noticed for all solids whatever the support used. Activities were calculated per gram of catalyst (Table 5), per square meter (Tables 6 and 7) and per atom of molybdenum (Tables 9 and 10) in order to 
evaluate the impact of each parameter. Regarding the global activity per gram $\left(\mathrm{A}_{\mathrm{T}}\right)$, CoMoS/50Ti@SBA-15 is the most active whereas the other catalysts have a similar activity except for $\mathrm{TiO}_{2}$ (P25) as support which leads to a very low activity mainly due to the low specific surface area (Table 6). This higher activity with 50Ti@SBA-15 as support is mainly due to the higher acid activity $\left(\mathrm{A}_{\mathrm{Acid}}\right)$ which corresponds to activity for isomerization and dismutation reactions. As reported in the literature [14], these reactions are due to the presence of the Bronsted acidity. As reported Table 3, xTi@SBA15 solids presented the high amount of pyridine adsorbed and also the most acid activity compared with alumina and P25 as supports. However, $\mathrm{CoMo} / \mathrm{Al}_{2} \mathrm{O}_{3}$ remains the catalyst with the highest $\mathrm{HDS}$ activity ( $\left.\mathrm{A}_{\mathrm{HDS}}\right)$ per gram which is more than 2 times more active than catalysts with pur $\mathrm{TiO}_{2}(\mathrm{P} 25)$ or xTi@SBA15 except 50Ti@SBA-15. This global HDS activity comes from mainly to DDS and HYD ways and also from DDS acid (around 17-13\% of selectivity) for the xTi@SBA-15 support. Differences are noticed with $\mathrm{TiO}_{2}$ (P25) and alumina supports. In fact, no contribution of the acid part is observed in both cases. The selectivities towards HYD and DDS are the same for $\mathrm{TiO}_{2}(\mathrm{P} 25)$ and mainly HYD way for the conventional alumina support. The modification of the selectivity between HYD and DDS way between CoMoS/xTi@SBA15 and the $\mathrm{CoMoS} / \mathrm{Al}_{2} \mathrm{O}_{3}$ reference catalyst leads to a decrease of the consumption of hydrogen during the HDS process of feedstocks. Taking into account the specific surface of the solid, CoMoS supported over alumina or $\mathrm{TiO}_{2}(\mathrm{P} 25)$ are the most active catalyst $\left(\mathrm{A}_{\text {total }}\right.$ and $\left.\mathrm{A}_{\mathrm{HDS}}\right)$ (Table 6). For the CoMoS/xTi@SBA-15 samples, the activities $\left(\mathrm{A}_{\text {total }}, \mathrm{A}_{\mathrm{HDS}}, \mathrm{A}_{\text {acid }}\right.$ and for the various ways of DDS) increase with the amount of Ti (Table 7). If we consider the activities per atom of molybdenum, which amount is very different for the various solids (3 atom.Mo per $\mathrm{nm}^{2}$ ) in one hand and that molybdenum atom is the active site in the other hand, it is possible to access to the intrinsic activity depending on the nature of the support. Indeed, as reported Table 9 and 10 respectively for the global, HDS and Acid activities (Table 9) and 
according to the different ways (DDS, HYD, DDS, DDS direct and DDS acid) (Table 10), the trends are conserved, the most active being $\mathrm{CoMoS} / \mathrm{Al}_{2} \mathrm{O}_{3}$ reference catalyst in $\mathrm{HDS}$ activities. For the xTi@SBA-15 support, the activities increase with the amount of titania in the support which could be to the presence of $\mathrm{TiO}_{2}$ with an anatase structure and/or a best dispersion of the active phase.

\section{Conclusion}

The results showed the benefit effect of the presence of a mixed xTi@SBA-15 in the catalytic performances for the transformation of 46DMDBT. The catalytic properties of the CoMoS/support depend strongly on the initial properties of the support used. Indeed, more the amount of $\mathrm{Ti}$ is, higher the catalytic activity for the transformation of 46DMDBT due to the presence of Brönsted acidity is. Regarding, the HDS activity, CoMoS supported over alumina remains the most active. Moreover, a modification of the selectivity between DDS and HYD ways was noticed using xTi@SBA15 support. In contrary with alumina as support, the direct DDS pathway becomes the main way, not attributed to the Brönsted acidity, but to the modification of the properties of the active phase. This is a significant parameter in order to reduce the consumption of hydrogen during HDS process of gas oils cuts.

\section{Conflict of interest statement}

The authors have no conflicts of interest to declare.

\section{Acknowledgments}

We would like to thank the platform "Spectroscopies et Microscopies des Interfaces" and Aurélien Renard (LCPME) for XPS analyses. The platform "X-ray diffusion" of IS2M is also acknowledged. 


\section{Appendix A. Supplementary data}

XRD diffraction at low angles (a) and wide angles (b) of xTi@SBA-15 supports (Fig. S1)

$\mathrm{N}_{2}$ adsorption/desorption isotherms of xTi@SBA-15 supports and variation of $\mathrm{S}_{\mathrm{BET}}$ with \%wt $\mathrm{TiO}_{2}$ (Fig. S2)

Ti (2p), Co (2p), Mo (3d) XPS spectra of 70Ti@SBA-15 (Fig. S3)

\section{References}

[1] S. Perez-Beltran, P. B. Baluena, G. E. Ramirez-Caballero, J. Phys. Chem. C, 120 (2016) $18105-18114$

[2] R. Huirache-Acuña, R. Nava, C. L. Peza-Ledesma, J. Lara-Romero, G. Alonso-Núñez, B. Pawelec, E. M. Rivera-Muñoz, Materials, 2013 (6) 4139-4167

[3] X. Chen, S. S. Mao, Chem. Rev., 2007 (107) 2891-2959.

[4] K. Zimny, T. Roques-Carmes, C. Carteret, M.-J. Stébé, J.-L. Blin, J. Phys. Chem. C, 116 (2012) 6585-6594

[5] S. Perathoner, P. Lanzafame, R. Passalacqua, G. Centi, R. Schlögl, D. S. Su, Microporous Mesoporous Mater., 90 (2006) 347-361

[6] D. J. Reidy, J. D. Holmes and M. A. Morris, Ceram. Int., 2006 (32) 235-239

[7] M. Bonne, S. Pronier, Y. Batonneau, F. Can, X. Courtois, S. Royer, P. Marescot and D.

Duprez, J. Mater. Chem., 2010 (20) 9205-9214

[8] M. Besançon, Laure Michelin, Ludovic Josien, Loic Vidal, Karine Assaker, Magali Bonne, Bénédicte Lebeau and Jean-Luc Blin, New J. Chem., 2016 (40) 4386-4397

[9] P. Castillo-Villalón, J. J. Ramírez, J. Catal., 2009 (268) 39-48

[10] W. Huang, A. Duan, Z. Zhao, G. Wan, G. Jiang, T. Dou, K. H. Chung, J. Liu, Catal. Today, 131 (2008) 314-321 
[11] M. T. Nguyen Dinh, . Rajbhandari, C. Lancelot, P. Blanchard, C. Lamonier, M. Bonne,

S. Royer, F. Dumeignil, E. Payen, Chem. Cat. Chem., 2014 (6) 328 - 338

[12] N. T. Tung, K. Imai, J. Pu, E. W. Qian, Energy Fuels, 2018 (32) 1665-1673

[13] T.A. Zepeda, Appl. Catal. A: General 347 (2008) 148-161

[14] G. Pérot, Catal. Today, 86 (2003) 111-128

[15] I. Naboulsi, C. Felipe Linares Aponte, B. Lebeau, S. Brunet, L. Michelin, M. Bonne, J.-L. Blin, Chem. Commun., 53 (2017) 2717-27-20

[16] I. Nabouli, B. Lebeau, C. Felipe Linares Aponte, S. Brunet, M. Mallet, L. Michelin, M. Bonne, C. Carteret, J.-L. Blin, Appl. Catal. A: General, 563 (2018) 91-97

[17] R Nava, R.A. Ortega, G. Alons, C. Ornelas, B. Pawelec, J. L.G. Fierro, Catal. Today, 127 (2017) 70-84

[18] O. Y. Gutierrez, G. A. Fuentes, C. Salcedo, T. Klimova, Catal. Today, 116 (2006) $485-497$

[19] S. A. Ganiyu, S. Ahmed Alic, K. Alhooshani, RSC Adv., 7 (2017) 21943-21952

[20] S. A. Ganiyu, S. Ahmed Alic, K. Alhooshani, Appl. Catal. B: Environmental, 203 (2017) 428-441

[21] T. T. Nguyen, Eika W. Qian, Microporous Mesoporous Mater., 265 (2018) 1-7

[22] M. S. Rana, S. K. Maity, J. Ancheyta, G. Murai Dhar, T. S. R. Prasada Rao, Appl. Catal. A: General, 253 (2003) 165-173

[23] D. Zhao, J. Feng, Q. Huo, N. Melosh, G. H. Fredrickson, B. F. Chmelka, G. D. Stucky, Science, 1998 (279) 548-552

[24] Y. Belmoujahid, M. Bonne, Y. Scudeller, D. Schleich, Y. Grohens, B. Lebeau, Microporous Mesoporous Mater., 2015 (201) 124-133

[25] S. Brunauer, P. H. Emmet, E. Teller, J. Am. Chem. Soc, 1938 (60) 309-319

[26] E. P. Barrett, L. G. Joyner, P. P. Halenda. J. Am. Chem. Soc., 1951 (73) 373-380 
[27] G. Greczynski and L. Hultman, Chem. Phys. Chem 2017 (18) 1507 -1512

[28] C. D. Wagner, W. M. Riggs, L. E. Davis, J. F. Moulder, in: G. E. Muilenberg (Ed.),

Handbook of X-ray Photoelectron Spectroscopy, Perkin-Elmer Corporation (PhysicalElectronics), 1979

[29] A. D. Gandubert, C. Legens, D. Guillaume, S. Rebours, E. Payen, Oil Gas Sci. Technol.Rev. IFP, 2007 (62) 79-87

[30] K. Marchand, C. Legens, D. Guillaume, P. Raybaud, Oil \& Gas Science and Technology

- Rev. IFP, 2009 (64) 719-730

[31] A. Platon and W. J. Thomson, Ind. Eng. Chem. Res., 2003 (42) 5988-5992

[32] S. Kelly, F.H. Pollak, M. Tomkiewicz, J. Phys. Chem. B, 1997 (101) 2730-2734

[33] W.F. Zhang, Y.L. He, M.S. Zhang, Z. Yin, Q. Chen, J. Phys. D: Appl. Phys., 2000 (33) ) $912-916$

[34] J. Lu, K. M. Kosuda, R. P. Van Duyne, P. C. Stair, J. Phys. Chem. C, 2009 (113) 12412 12418

[35] M. Egorova, R. Prins, J. Catal. 2004 (224) 278-287

[36] M. Digne, K. Marchand, P. Bourges, Oil \& Gas Science and Technology - Rev. IFP, 2007 (62) 91-99

[37] P. Mazoyer, C. Geantet, F. Diehl, S. Loridant, M. Lacroix, Catal. Today, 130 (2008) 7579

[38] P. Michaud, J.L. Lemberton and G. Pérot, Appl. Catal. A, 1998 (169) 343-353

[39] M.J. Girgis and B.C. Gates, Ind. Eng. Chem. Res., 1991 (30) 2021-2028

[40] I. Naboulsi, B. Lebeau, L. Michelin, C. Carteret, L. Vidal, M. Bonne and J.L. Blin, ACS Appl. Mater. Interfaces 2017 (9) 3113-3122

[41] H. Li, M. Vrinat, G. Berhault, D. Li, H. Nie and P. Afanasiev, Mater. Res. Bull. 2013

(48) 3374-3382 
Scheme 1. Transformation of 46DMDBT. (HYD: Hydrogenation way, DDS: Direct Desulfurization way, sulf: sulfide phase, acid: acid properties, Dism: Dismutation, Isom: Isomerization. 46DMDBT: 4,6 dimethyldibenzothiophene, MCHMB, Methylcyclohexylmethylbenzene, MBPh: methylbiphenyl, DMDBT: dimethyldibenzothiophene, DMBPh: dimethylbiphenyl, TMDBT: trimethylbiphenyl, MBPh: methylbiphenyl)

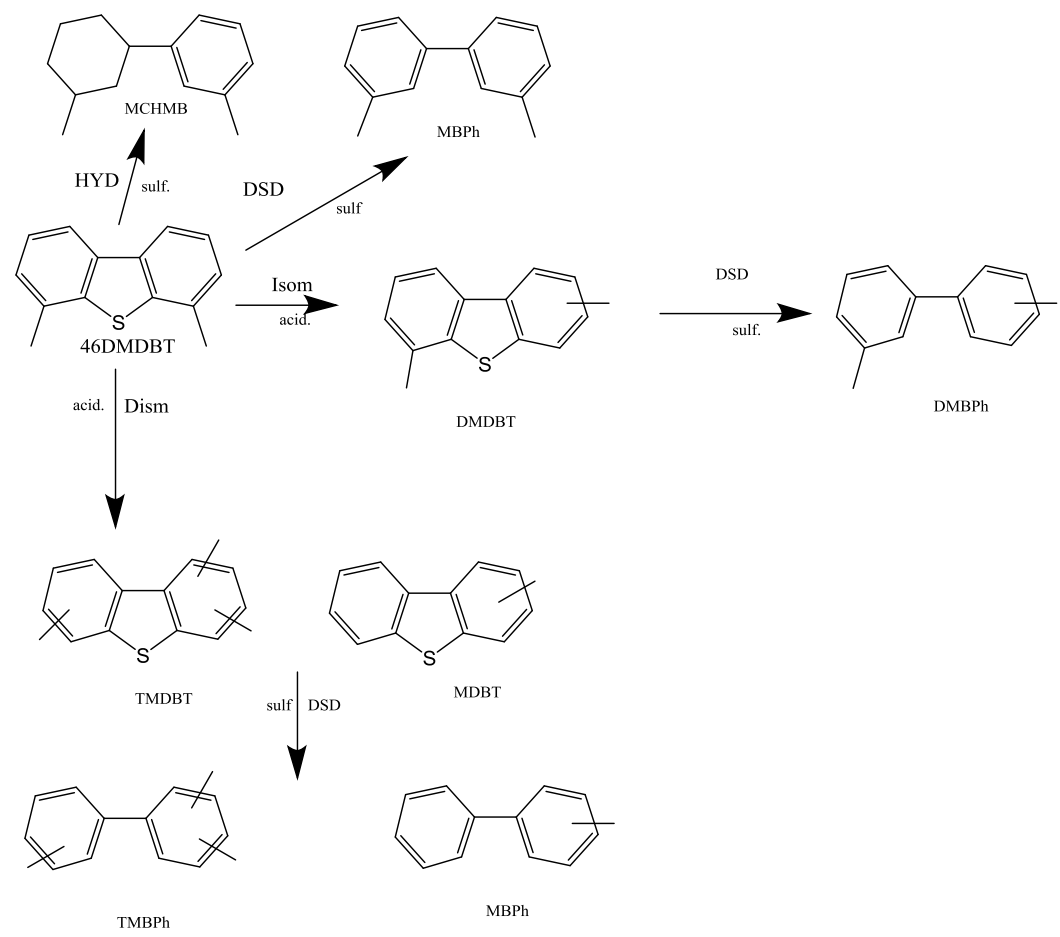


Table 1. Specific surface area $\left(\mathrm{S}_{\mathrm{BET}}\right)$, pore diameter $(\varnothing)$ and mesopore pore volume $\left(\mathrm{V}_{\mathrm{P}}\right)$ of the supports before and after CoMo impregnation

\begin{tabular}{ccccccc}
\hline & \multicolumn{3}{c}{ Before impregnation } & \multicolumn{3}{c}{ After impregnation } \\
\cline { 2 - 6 } Support & $\begin{array}{c}\mathrm{S}_{\mathrm{BET}} \\
\left(\mathrm{m}^{2} \cdot \mathrm{g}^{-1}\right)\end{array}$ & $\varnothing(\mathrm{nm})^{*}$ & $\begin{array}{c}\mathrm{Vp}^{*} \\
\left(\mathrm{~cm}^{3} \cdot \mathrm{g}^{-1}\right)\end{array}$ & $\begin{array}{c}\mathrm{S}_{\mathrm{BET}} \\
\left(\mathrm{m}^{2} \cdot \mathrm{g}^{-1}\right)\end{array}$ & $\varnothing(\mathrm{nm})^{*}$ & $\begin{array}{c}\mathrm{Vp}^{*} \\
\left(\mathrm{~cm}^{3} \cdot \mathrm{g}^{-1}\right)\end{array}$ \\
\hline P25 & 37 & - & 0.52 & 37 & - & 0.09 \\
SBA-15 & 989 & 6.0 & 1.06 & 247 & 7.5 & 0.28 \\
25Ti@SBA-15 & 712 & 5.2 & 0.74 & 204 & 6.0 & 0.22 \\
50Ti@SBA-15 & 451 & 4.0 & 0.41 & 235 & 4.3 & 0.19 \\
70Ti@SBA-15 & 251 & 3.9 & 0.21 & 92 & 5.2 & 0.08 \\
\hline * Values determined from the BJH method applied to the adsorption branch of the isotherm
\end{tabular}


Table 2. Amount of molybdenum and cobalt in the $\mathrm{CoMo} / \mathrm{support}$ determined by spectroscopy of X-ray fluorescence and XPS (values in bracket)

\begin{tabular}{cccc}
\hline Support & Co/Mo & Co/(Co+Mo $)$ & Mo (at/nm $\left.{ }^{2}\right)$ \\
\hline SBA-15 & $(0.70)^{*}$ & $(0.41)^{*}$ & - \\
25Ti@SBA-15 & $0.71(0.55)^{*}$ & $0.42(0.36)^{*}$ & 2.50 \\
50Ti@SBA-15 & $0.62(0.57)^{*}$ & $0.38(0.36)^{*}$ & 2.54 \\
$70 \mathrm{Ti} @$ SBA-15 & $0.66(0.54)^{*}$ & $0.40(0.35)^{*}$ & 2.42 \\
$\mathrm{TiO}_{2}(\mathrm{P} 25)$ & 0.64 & 0.39 & 3.42 \\
\hline
\end{tabular}

*determined by XPS spectroscopy 
Table 3. Values of acidity determined by pyridine adsorption followed by FTIR of the various CoMo/support (L : Lewis, B : Brönsted)

\begin{tabular}{|c|c|c|c|c|c|c|c|}
\hline Support & & SBA15 & $\begin{array}{c}25 \mathrm{Ti} @ \mathrm{SBA}- \\
15\end{array}$ & $\begin{array}{c}\text { 50Ti@SBA- } \\
15\end{array}$ & $\begin{array}{c}\text { 75Ti@SBA- } \\
15\end{array}$ & $\begin{array}{l}\mathrm{TiO}_{2} \\
(\mathrm{P} 25)\end{array}$ & $\mathrm{Al}_{2} \mathrm{O}_{3}$ \\
\hline & $\mathrm{L}$ & 213 & 322 & 164 & 132 & 140 & 140 \\
\hline $\begin{array}{c}\mathrm{n}_{\mathrm{pyr}}{ }^{-1} \\
\left(\mu \mathrm{mol}^{-1}\right)\end{array}$ & $\mathrm{B}$ & 8 & 24 & 19 & 14 & 3 & 0 \\
\hline & $\mathrm{L}$ & 0.86 & 1.6 & 0.70 & 1.4 & 3.8 & 1.1 \\
\hline $\begin{array}{c}\mathrm{n}_{\mathrm{pyr}}-2 \\
\left(\mu \mathrm{mol}^{-2}\right)\end{array}$ & B & 0.03 & 0.1 & 0.08 & 0.15 & 0.08 & 0 \\
\hline
\end{tabular}


Table 4. XPS characterization of CoMoS/ support catalysts: S/Mo, Co/Mo and (Co/Mo $)_{\text {slabs }}$ atomic ratios, promotion rate by cobalt (PR\%) and, sulfidation rate of molydenum (TSMo \%) and Total sulfidation rate (TSG).

\begin{tabular}{ccccccc}
\hline Support & TSMo $(\%)$ & $\begin{array}{c}\text { TSG } \\
(\%)\end{array}$ & $\begin{array}{c}\mathrm{PR}^{\mathrm{a}} \\
(\%)\end{array}$ & S/Mo & Co/Mo & $(\mathrm{Co} / \mathrm{Mo})^{\mathrm{b}}{ }_{\text {slabs }}$ \\
\hline SBA15 & 71 & 59 & 21 & 1.8 & 0.7 & 0.21 \\
25Ti@SBA-15 & 62 & 60 & 49 & 1.8 & 0.4 & 0.30 \\
$70 \mathrm{Ti} @ \mathrm{SBA}^{2} 15$ & 58 & 64 & 35 & 2.0 & 0.5 & 0.29 \\
$\mathrm{TiO}_{2}(\mathrm{P} 25)^{*}$ & 40 & 71 & 13 & 2.3 & 0.4 & 0.13 \\
\hline $\mathrm{Al}_{2} \mathrm{O}_{3}{ }^{*}$ & 70 & 53 & 26 & 1.5 & 0.3 & 0.10 \\
\hline
\end{tabular}

"used as $\mathrm{TiO}_{2}$ reference

** used as reference for HDS reactions

${ }^{\mathrm{a}}: \mathrm{PR}=\frac{[\mathrm{CoMoS}]}{[\mathrm{Co}]_{\text {Total }}} \times 100$

${ }^{\mathrm{b}}$ : The promoter ratio is the $\mathrm{Co} / \mathrm{Mo}$ ratio in the slabs $\left[(\mathrm{Co} / \mathrm{Mo})_{\text {slabs }}\right]$

$$
\left(\frac{\mathrm{Co}}{\mathrm{Mo}}\right)_{\text {Slabs }}=\frac{[\mathrm{CoMoS}]}{\mathrm{MoS}_{2}}
$$


Table 5. Repartition of the various phases from XPS data for the different supported CoMoS catalysts

\begin{tabular}{|c|c|c|c|c|c|c|c|c|c|c|}
\hline \multirow{2}{*}{ Support } & \multicolumn{3}{|c|}{ Mo repartition (at.\%) } & \multicolumn{3}{|c|}{ Co repartition (at.\%) } & \multicolumn{4}{|c|}{ S repartition (at.\%) } \\
\hline & $\mathrm{MoS}_{2}$ & Mo 5+ & $\mathrm{MoO}_{3}$ & CoMoS & $\mathrm{Co}_{9} \mathrm{~S}_{8}$ & $\mathrm{CoO}$ & Sulf. & $\mathrm{S}^{0}$ & $\mathrm{SO}_{\mathrm{x}}$ & Sulfates \\
\hline SBA-15 & 71 & 17 & 13 & 20.9 & 50.0 & 29.1 & 100 & 0 & 0 & 0 \\
\hline 25i@SBA-15 & 62 & 27 & 11 & 49.0 & 22.0 & 29.0 & 83.9 & 16.1 & 0 & 0 \\
\hline 70Ti@SBA-15 & 58 & 36 & 6 & 35.3 & 36.0 & 28.7 & 85.2 & 14.8 & 0 & 0 \\
\hline $\mathrm{P} 25^{*}$ & 40 & 30 & 30 & 12.9 & 10.2 & 76.9 & 56.8 & 15.8 & 18.6 & 8.8 \\
\hline$\gamma-\mathrm{Al}_{2} \mathrm{O}_{3}{ }^{* *}$ & 70 & 15 & 15 & 25.7 & 52.3 & 22 & 100 & 0 & 0 & 0 \\
\hline
\end{tabular}


Table 6. Transformation of 46DMDBT over CoMoS/support catalysts - Activity and selectivity from the different pathways. $\left(\mathrm{T}=340^{\circ} \mathrm{C}, \mathrm{P}=4 \mathrm{MPa}\right)$

Activity (A mmol h $\left.\mathrm{g}^{-1}\right) \quad$ Selectivity $(\%)$

\begin{tabular}{|c|c|c|c|c|c|c|c|}
\hline Support & $\mathrm{A}_{\mathrm{T}}$ & $\mathrm{A}_{\text {Acid }}$ & $\mathrm{A}_{\mathrm{HDS}}$ & HYD & $\begin{array}{c}\text { DDS } \\
\text { Direct }\end{array}$ & $\begin{array}{l}\text { DDS } \\
\text { Acid }\end{array}$ & HYD/DDS \\
\hline $\mathrm{TiO}_{2}(\mathrm{P} 25)$ & 0.24 & 0.04 & 0.20 & 50 & 50 & 0 & 1 \\
\hline 70Ti@SBA-15 & 0.68 & 0.45 & 0.23 & 35 & 48 & 17 & 0.53 \\
\hline 50Ti@SBA-15 & 1.05 & 0.65 & 0.4 & 43 & 40 & 17 & 0.74 \\
\hline 25Ti@SBA-15 & 0.8 & 0.49 & 0.31 & 39 & 48 & 13 & 0.63 \\
\hline SBA-15 & 0.75 & 0.23 & 0.52 & 37 & 44 & 19 & 0.57 \\
\hline $\mathrm{Al}_{2} \mathrm{O}_{3}$ & 0.73 & 0 & 0.73 & 77 & 25 & 0 & 3.1 \\
\hline
\end{tabular}

$\mathrm{A}_{\text {total }}:$ total activity $=\mathrm{A}_{\mathrm{HDS}}+\mathrm{A}_{\text {acid }}$

$\mathrm{A}_{\mathrm{acid}}$ : activity for isomerization + activity for dismutation of 46 DMDBT into alkyldibenzothiophene $\mathrm{A}_{\text {total HDS }}=$ total activity for 46DMDBT HDSHYD: selectivity towards HDS by HYD route (formation of dimethylcyclhexyltoluene)

DDS direct: selectivity towards HDS by direct C-S bond from 46DMDBT (formation of dimethylbiphenyl)

DDS acid: selectivity towards HDS by direct C-S bond from dimustation and isomerization products of 46DMDBT (formation of dimethylbiphenyls) 
Table 7. Transformation of 46DMDBT over CoMoS/support catalysts - HDS activities from the different ways per square meter $\left(\right.$ mmole h $\left.^{-1} . \mathrm{m}^{-2}\right) \times 10^{-3}\left(\mathrm{~T}=340^{\circ} \mathrm{C}, \mathrm{P}=4 \mathrm{MPa}\right)$

\begin{tabular}{cccc}
\hline Support & $\mathrm{A}_{\text {totale }}$ & $\mathrm{A}_{\mathrm{HDS}}$ & $\mathrm{A}_{\text {Acid }}$ \\
\hline $\mathrm{TiO}_{2}(\mathrm{P} 25)$ & 6.4 & 5.4 & 1. \\
\hline 70Ti@SBA-15 & 7.0 & 2.5 & 4.5 \\
50Ti@SBA-15 & 4.5 & 1.7 & 2.8 \\
25Ti@SBA-15 & 3.9 & 1.5 & 2.4 \\
\hline SBA-15 & 2.9 & 2.0 & 0.9 \\
\hline $\mathrm{Al}_{2} \mathrm{O}_{3}$ & 6.0 & 6.0 & 0 \\
\hline
\end{tabular}


Table 8. Transformation of 46DMDBT over CoMoS/support catalysts - HDS activities from the different ways per square meter $\left(\mathrm{mmol} \mathrm{h}^{-1} \mathrm{~m}^{-2}\right) \times 10^{-3}\left(\mathrm{~T}=340^{\circ} \mathrm{C}, \mathrm{P}=4 \mathrm{MPa}\right)$

\begin{tabular}{cccccc}
\hline Support & $\mathrm{A}_{\mathrm{HDS}}$ & $\mathrm{A}_{\mathrm{HYD}}$ & $\mathrm{A}_{\text {DDS }}$ & $\mathrm{A}_{\text {DDS direct }}$ & $\mathrm{A}_{\text {DDS Acid }}$ \\
\hline $\mathrm{TiO}_{2}(\mathrm{P} 25)$ & 5.4 & 0.27 & 0.27 & 0.27 & 0 \\
\hline 70Ti@SBA-15 & 2.5 & 0.9 & 1.6 & 1.2 & 0.4 \\
50Ti@SBA-15 & 1.7 & 0.7 & 1.0 & 0.70 & 0.3 \\
25Ti@SBA-15 & 1.5 & 0.75 & 0.75 & 0.75 & 0 \\
\hline SBA-15 & 2.0 & 0.7 & 1.3 & 0.9 & 0.4 \\
\hline $\mathrm{Al}_{2} \mathrm{O}_{3}$ & 6 & 4.5 & 1.5 & 1.5 & 0 \\
\hline
\end{tabular}


Table 9. Transformation of 46DMDBT over CoMoS/support catalysts - HDS activities from the different ways per Mo (mmole $\mathrm{h}^{-1} \mathrm{Mo}^{-1}$ atom. $\left.^{-1}\right) \times 10^{-21}\left(\mathrm{~T}=340^{\circ} \mathrm{C}, \mathrm{P}=4 \mathrm{MPa}\right)$

\begin{tabular}{cccc}
\hline Support & $\mathrm{A}_{\text {totale }}$ & $\mathrm{A}_{\mathrm{HDS}}$ & $\mathrm{A}_{\text {Acid }}$ \\
\hline $\mathrm{TiO}_{2}(\mathrm{P} 25)$ & 0.21 & 0.18 & 0.03 \\
\hline 70Ti@SBA-15 & 2.5 & 0.9 & 1.6 \\
50Ti@SBA-15 & 1.5 & 0.6 & 0.9 \\
25Ti@SBA-15 & 1.3 & 0.5 & 0.8 \\
\hline SBA-15 & 1.0 & 0.7 & 0.3 \\
\hline $\mathrm{Al}_{2} \mathrm{O}_{3}$ & 2.0 & 2.0 & 0 \\
\hline
\end{tabular}


Table 10. Transformation of 46DMDBT over CoMoS/support catalysts - HDS activities from the different ways per Mo atom (mmole $\mathrm{h}^{-1} \mathrm{Mo}$ atom. $\left.^{-1}\right) \times 10^{-21}\left(\mathrm{~T}=340^{\circ} \mathrm{C}, \mathrm{P}=4 \mathrm{MPa}\right)$

\begin{tabular}{cccccc}
\hline Support & $\mathrm{A}_{\mathrm{HDS}}$ & $\mathrm{A}_{\mathrm{HYD}}$ & $\mathrm{A}_{\mathrm{DDS}}$ & $\mathrm{A}_{\text {DDS direct }}$ & $\mathrm{A}_{\text {DDS Acid }}$ \\
\hline $\mathrm{TiO}_{2}(\mathrm{P} 25)$ & 0.18 & 0.09 & 0.09 & 0.09 & 0 \\
\hline 70Ti@SBA-15 & 0.83 & 0.30 & 0.53 & 0.40 & 0.13 \\
50Ti@SBA-15 & 0.57 & 0.20 & 0.33 & 0.23 & 0.10 \\
\hline 25Ti@SBA-15 & 0.50 & 0.20 & 0.30 & 0.25 & 0.05 \\
\hline SBA-15 & 0.67 & 0.23 & 0.43 & 0.30 & 0.13 \\
\hline $\mathrm{Al}_{2} \mathrm{O}_{3}$ & 2.0 & 1.5 & 05 & 0.5 & 0 \\
\hline
\end{tabular}




\section{Figure captions}

Fig. 1. (a) Raman and (b) UV-VIS spectra of Ti@ SBA-15 supports

Fig. 2. Raman spectra of CoMo/xTi@SBA-15 catalysts

Fig. 3. Mo 3d a), Co 2p b) and S 2p c) XPS spectra of the CoMoS/70Ti@SBA-15 catalyst

Fig. 4. TEM images of CoMoS/50Ti@SBA-15 a) SBA-15 and b) $\mathrm{TiO}_{2}$ crystals

Fig. 5. TEM images of CoMoS/70Ti@SBA-15 a) SBA-15 and b) $\mathrm{TiO}_{2}$ crystals

Fig. 6. TEM image of a) CoMoS/SBA-15 and b) $\mathrm{CoMoS} / \mathrm{Al}_{2} \mathrm{O}_{3}$ 
Fig. 1. (a) Raman and (b) UV-VIS spectra of Ti@ SBA-15 supports
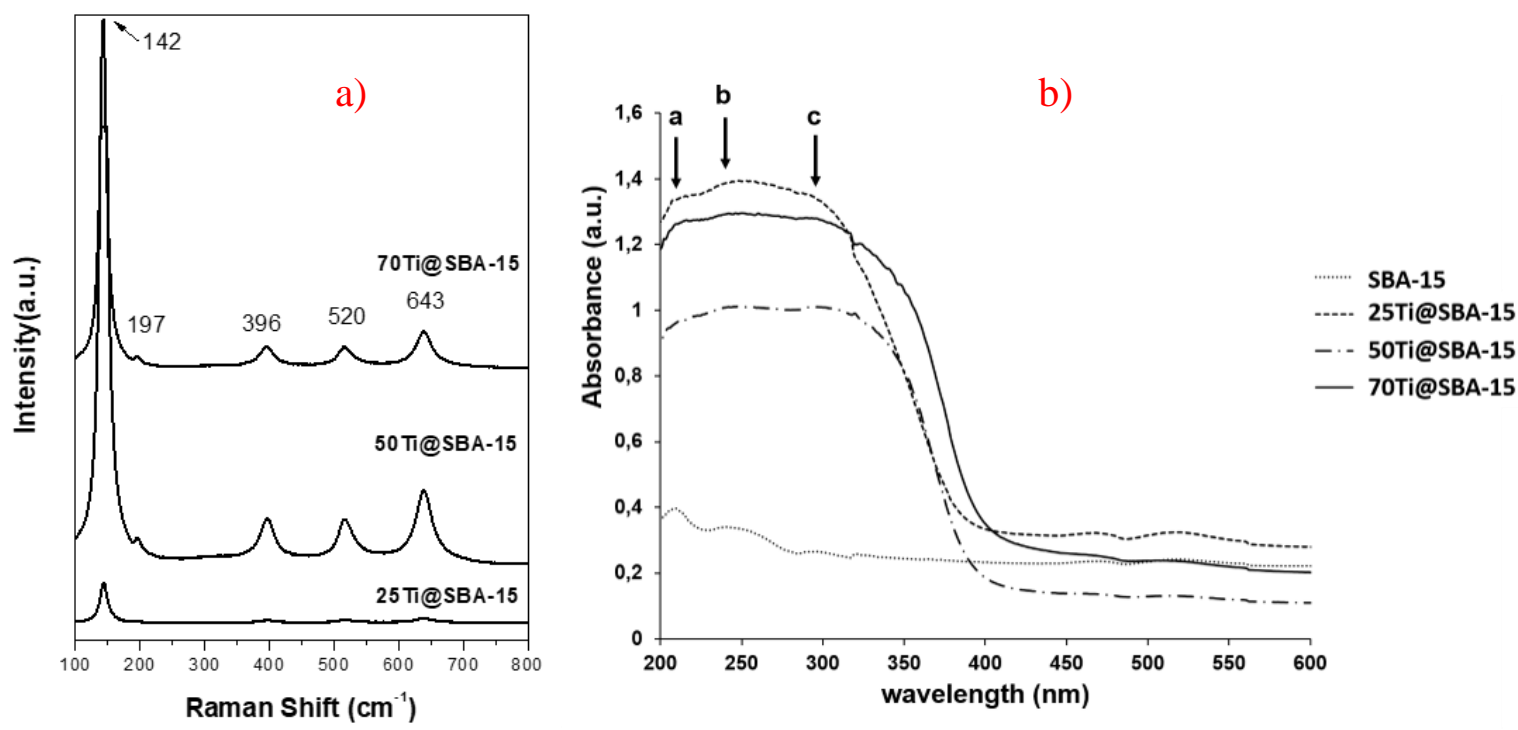
Fig. 2. Raman spectra of CoMo/xTi@SBA-15 catalysts
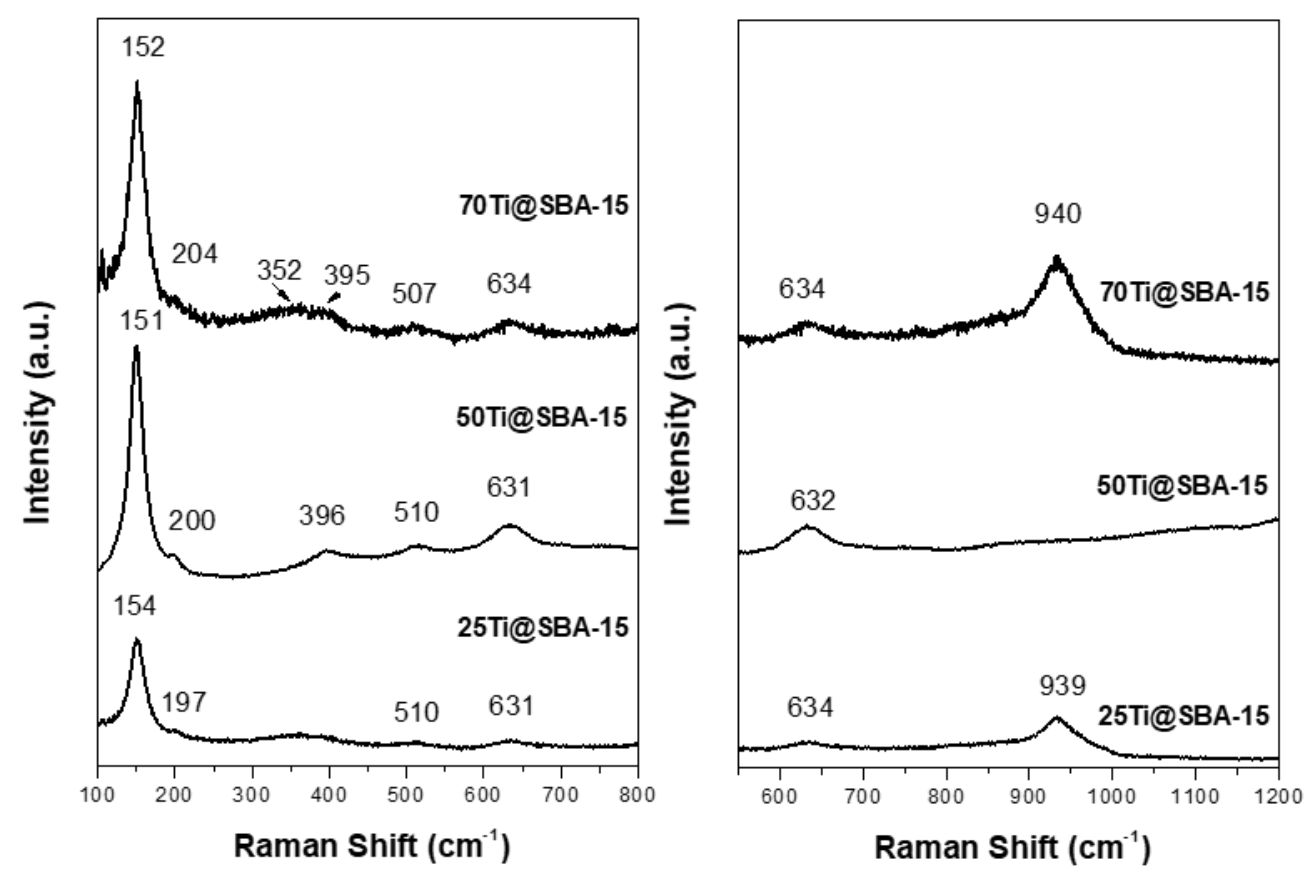
Fig. 3. Mo 3d a), Co 2p b) and S 2p c) XPS spectra of the CoMoS/70Ti@SBA-15 catalyst
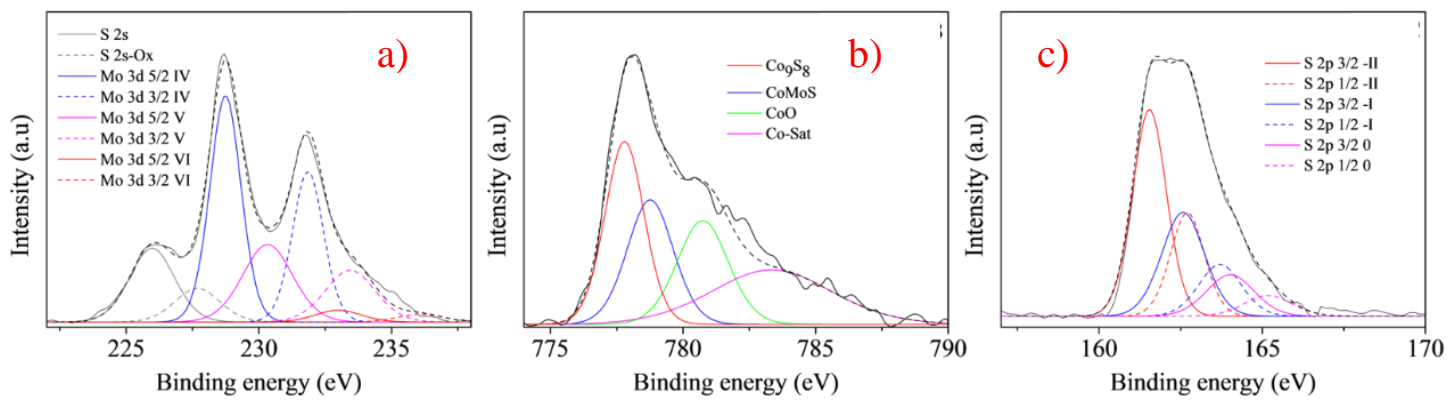
Fig. 4. TEM images of CoMoS/50Ti@SBA-15 a) SBA-15 and b) $\mathrm{TiO}_{2}$ crystals

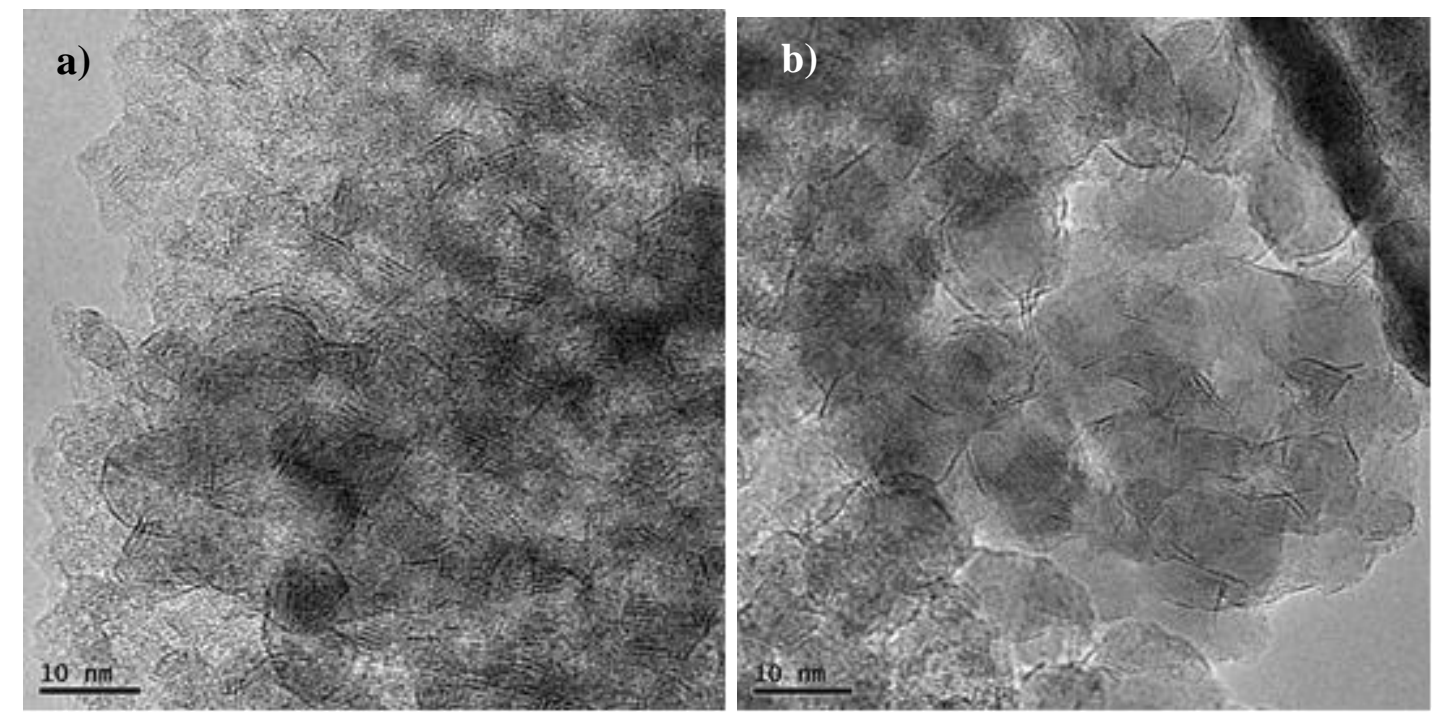

a) $\mathrm{MoS}_{2}$ slab isolated with a stacking from 1 to 5 slabs and a length of slab of $5 \mathrm{~nm}$

b) $\mathrm{MoS}_{2}$ slab surround the $\mathrm{TiO}_{2}$ crystals, with a stacking from 1 to 3 and a length of slab from 10 to $20 \mathrm{~nm}$. 
Fig. 5. TEM images of CoMoS/70Ti@SBA-15 a) SBA-15 and b) $\mathrm{TiO}_{2}$ crystals

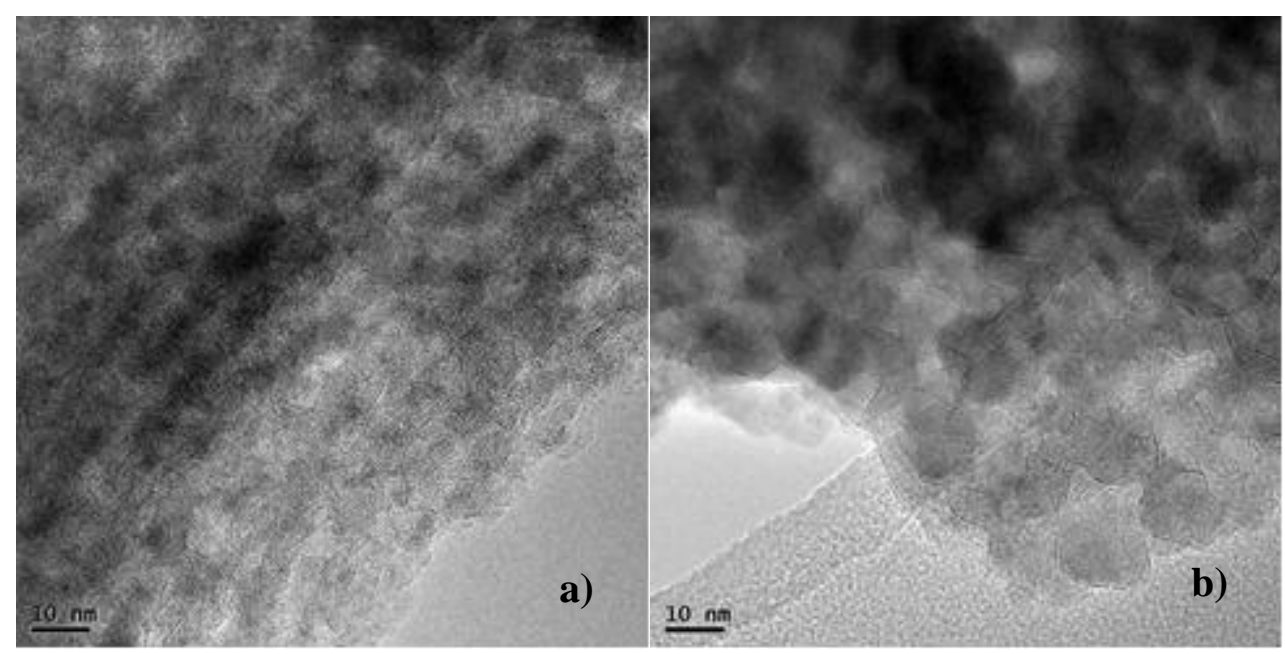

a) $\mathrm{MoS}_{2}$ slab isolated with a stacking from 1 to 5 slabs and a length of slab of $5 \mathrm{~nm}$

b) $\mathrm{MoS}_{2}$ slab surround the $\mathrm{TiO}_{2}$ crystals, with a stacking from 1 to 2 and a length of slab from 10 to $20 \mathrm{~nm}$. 
Fig. 6. TEM image of a) CoMoS/SBA-15 and b) $\mathrm{CoMoS} / \mathrm{Al}_{2} \mathrm{O}_{3}$
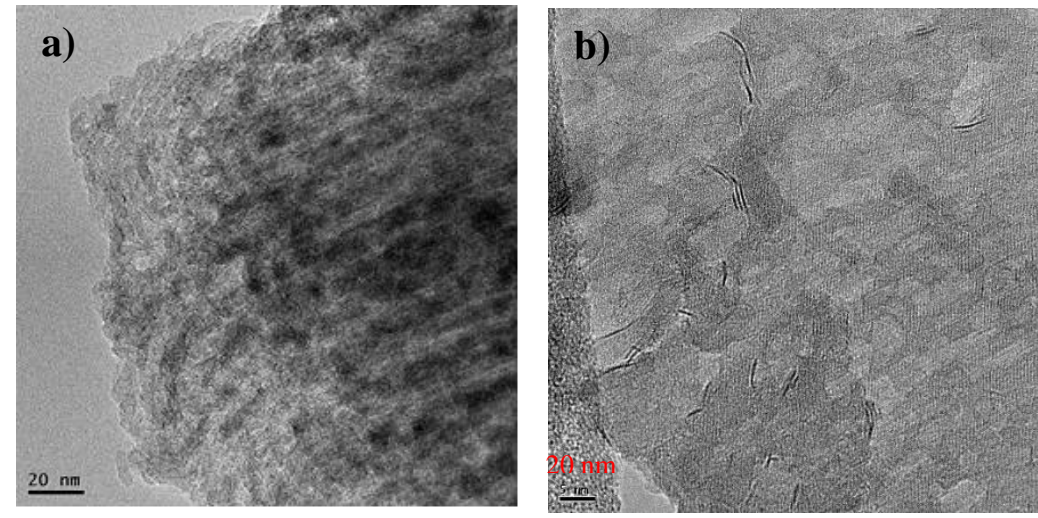

a) Length of $\mathrm{MoS}_{2}$ slabs lower than $10 \mathrm{~nm}$ and a stacking from 1 to 6 slabs

b) Length of $\mathrm{MoS}_{2}$ slabs between 20 than $50 \mathrm{~nm}$ and a stacking from 1 to 3 slabs 


\section{Supplementary Information}

\section{HDS of 4,6-dimethyldibenzothiophene over CoMoS supported mesoporous}

$\mathrm{SiO}_{2}-\mathrm{TiO}_{2}$ materials

B. Lebeau ${ }^{1,2^{*}}$, M. Bonne ${ }^{1,2}$, J.D Comparot $^{3}$, J. Rousseau ${ }^{3}$, L. Michelin ${ }^{1,2}$, J. L. Blin ${ }^{4}$, S. Brunet $^{3 *}$

${ }^{1}$ Université de Haute Alsace (UHA), CNRS, Institut de Science des Matériaux de Mulhouse (IS2M) UMR 7361, F-68100 Mulhouse, France,

${ }^{2}$ Université de Strasbourg, France

${ }^{3}$ Université de Poitiers /CNRS, IC2MP, UMR 7285, 86073 Poitiers Cedex 9 France.

${ }^{4}$ Université de Lorraine/CNRS, L2CM, UMR 7053, 54500 Vandoeuvre-lès-Nancy, France 

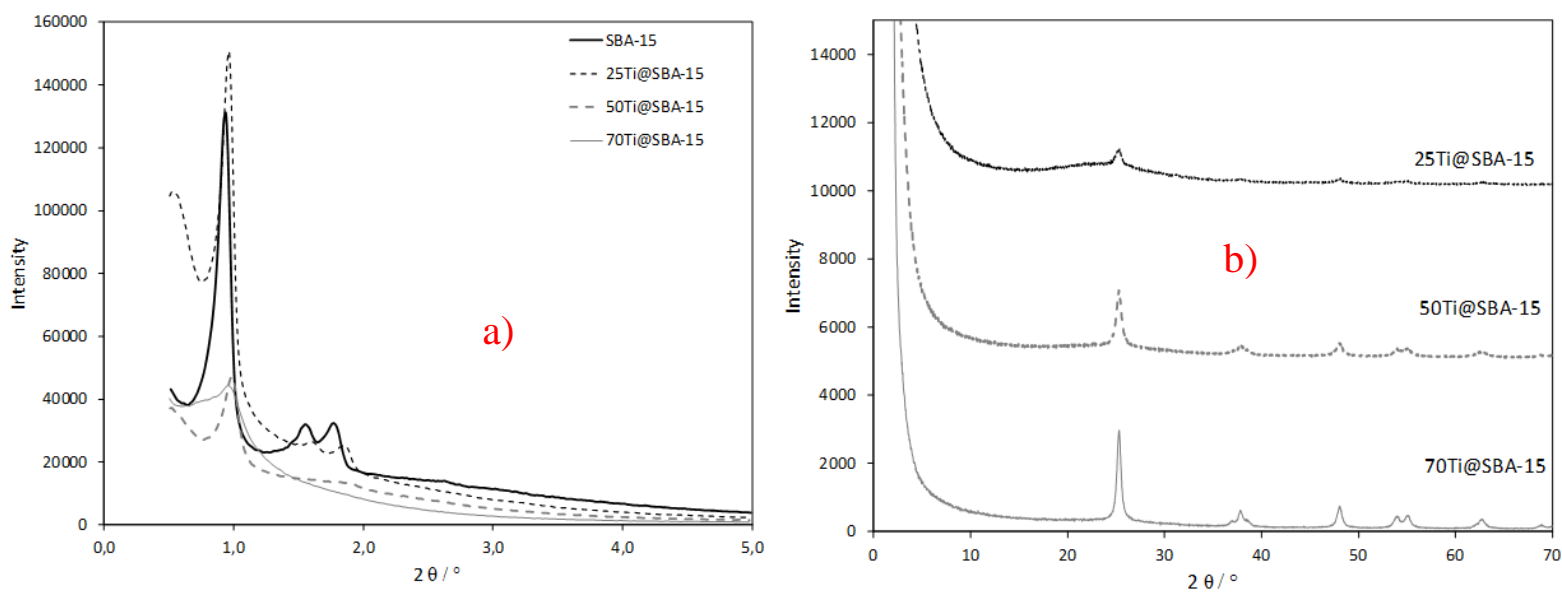

Fig. S1. XRD diffraction at low angles (a) and wide angles (b) of xTi@SBA-15 supports 

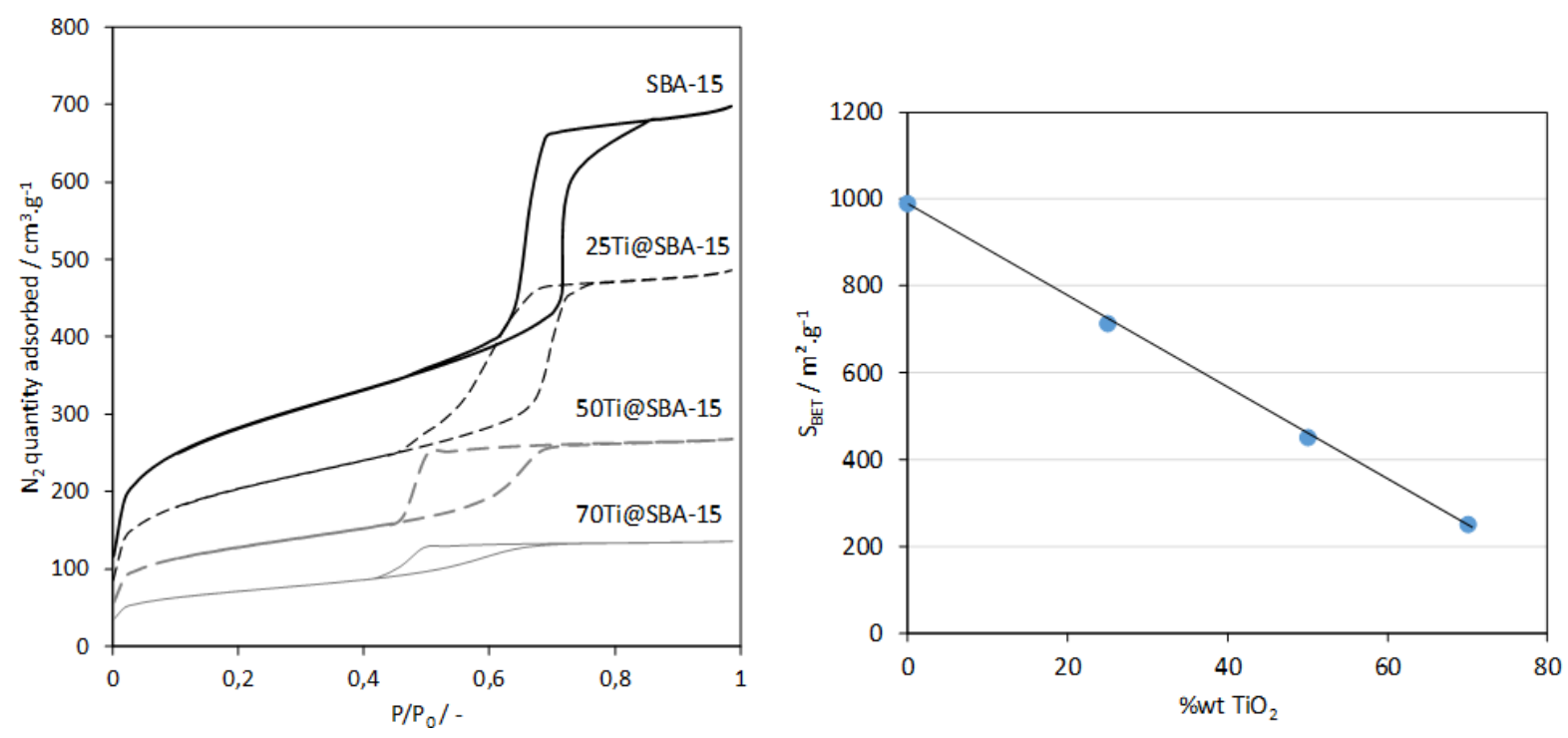

Fig. S2. $\mathrm{N}_{2}$ adsorption/desorption isotherms of xTi@SBA-15 supports and variation of $\mathrm{S}_{\mathrm{BET}}$ with $\%$ wt $\mathrm{TiO}_{2}$ 

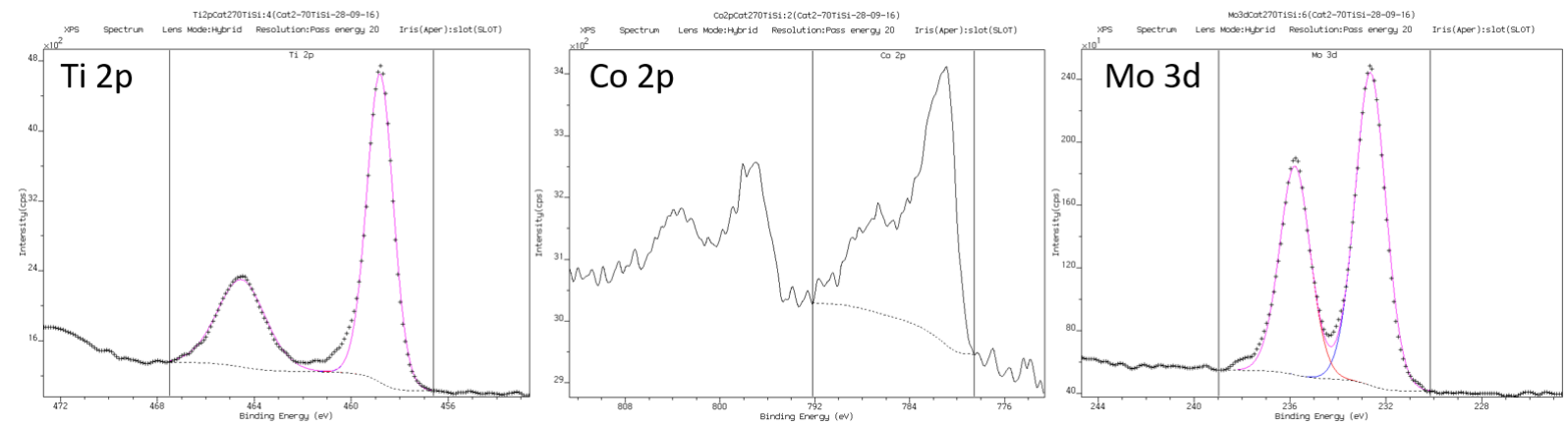

Fig. S3. Ti (2p), Co (2p), Mo (3d) XPS spectra of 70Ti@SBA-15 


\section{Suggested reviewers :}

1. Dr. Viorica Parvulescu

Senior Researcher I

"Ilie Murgulescu" Institute of Physical Chemistry of Romanian Academy

Department Chemistry of Surface and Catalysis

Head of research group Catalytic Processes and Materials

Splaiul Independentei 202 Bucharest

Romania

E-mail : vpirvulescu@icf.ro

\section{Prof. Stéphane Siffert}

Unité de Chimie Environnementale et Interactions sur le Vivant (UCEIV) EA-4492

Axe 2: Remédiation et valorisation - Traitement catalytique et énergie propre

MREI 1 - Université du Littoral - Côte d'Opale

145, avenue Maurice Schumann

59140 Dunkerque

France

Email : Stephane.Siffert@univ-littoral.fr

3. Prof. Silvia Todorova

Director of Institute of Catalysis

Bulgarian Academy of Sciences

Acad. G. Bonchev St. Block 11

1113 Sofia,

Bulgaria

E-mail : todorova@ic.bas.bg

4. Prof. Yu Li

Laboratory of Living Materials at the State Key Laboratory of Advanced Technology for Materials Synthesis and Processing

Wuhan University of Technology

122 Luoshi Road, 430070

Wuhan, Hubei, China

E-mail: yu.li@whut.edu.cn 